\title{
TRADIÇÃO E VANGUARDA NA CONSOLIDAÇÃO DA LÍRICA MODERNA EM PORTUGAL
}

Maria Lúcia Outeiro Fernandes ${ }^{1}$

Recebido: 18/04/2016

Aprovado: 15/05/2016

\begin{abstract}
RESUMO: Num primeiro momento, este trabalho focaliza algumas relações possíveis entre conceitos-chave para se entender a arte no século XX, tais como moderno, modernidade e modernismo, buscando delinear o papel da Geração de Orpheu na modernização da lírica portuguesa. Num segundo momento, analisa alguns aspectos do diálogo e das tensões entre tradição e vanguarda, verificados durante o processo de modernização da poesia portuguesa, especialmente na obra de Fernando Pessoa.

PALAVRAS-CHAVE: Lírica Moderna; Modernismo; Fernando Pessoa; Geração de Orpheu; Vanguardas.

\section{TRADITION AND VANGUARD IN THE CONSOLIDATION OF THE MODERN LYRIC IN PORTUGAL}

\begin{abstract}
At first, this paper emphasizes some possible relations between key-concepts - such as the modern, modernity and modernism - to understand art in the 20th century in order to trace the role of Orpheus' Generation regarding the modern improvement of Portuguese poetry. In a second moment, the paper presents an analysis of some aspects related to the dialogue and the tensions between tradition and vanguard that were found during the process of modernization of Portuguese poetry, especially in the works of Fernando Pessoa.
\end{abstract}

KEYWORDS: Modern Lyric; Modernism; Fernando Pessoa; Orpheus' Generation; Vanguards.

Tradição e vanguarda articulam-se, na obra dos escritores da Geração de Orpheu, para consolidar uma lírica moderna que se insere numa estética já estabelecida em grande parte da Europa desde os primeiros românticos, denominada por Octavio Paz como “tradição da ruptura” (1984, p. 17). Além de Paz, outro teórico que fornece subsídios importantes para a reflexão que vamos desenvolver neste texto é Mattei Calinescu (1987), para quem os conceitos de moderno, modernidade, modernismo e vanguarda remetem a uma ideia comum, de crescente relativismo histórico, firmado a partir do romantismo.

\footnotetext{
1 Docente do Departamento de Literatura e do Programa de Pós-Graduação em Estudos Literários, da Faculdade de Filosofia e Letras da UNESP, campus de Araraquara.
} 


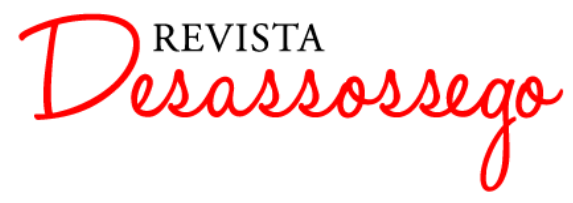

DESASSOSSEGO 15 | JUN/2016 | ISSN 2175-3180

DOI: http://dx.doi.org/10.11606/issn.2175-3180.v8i15p6-16

Com a valorização do moderno, na arte ocidental, avulta a ideia de que o passado não tem mais caráter normativo, que a tradição deixa de ter legitimidade para estabelecer modelos ou impor direções aos artistas. A modernidade estética, tomada neste sentido amplo, resulta da passagem de uma estética da permanência, baseada na crença de uma beleza imutável e transcendente, para uma estética da transitoriedade e da imanência, tal como se verifica em muitos manifestos de vanguarda, como ocorre no texto dadaísta "Proclamação Sem Pretensão": "Eu escrevo porque é natural (...). Não buscamos a força direita PURA SÓBRIA única nós não buscamos NADA nós afirmamos a VITALIDADE de cada instante" (TELES, 1972, p. 117).

Tal transição histórica, porém, não ocorreu de repente, nem de maneira tranquila e definitiva, no sentido de que uma estética tenha simplesmente substituído a outra. Quando percorremos os caminhos da modernidade, desde a sua formação, em meados do século XIX, até seus desdobramentos contemporâneos, passando pelas manifestações modernistas, verificamos uma variada e complexa relação entre o impulso para o novo e a busca de permanência, articulada com outras tensões e contradições.

Consagrada por Baudelaire como nova estética, a modernidade aponta para a consolidação de uma mentalidade que, mesmo quando se refere ao passado, não o toma mais como paradigma incorruptível. Heróis e mitos antigos, quando revisitados, servem de contraponto para uma reflexão do artista acerca dos aspectos que resultam de seu mergulho nos fenômenos do presente, momento em que se depara com angústias e conflitos vivenciados pelo sujeito no seu contexto contemporâneo. $\mathrm{Na}$ estética moderna, ideais de perfeição, quando vislumbrados, são projetados ora numa fugidia transcendência criada pela obra de arte, ora no futuro, mas nunca no passado.

Por este viés, pode-se considerar que os escritores românticos, ao reagirem contra $\mathrm{O}$ conceito universal e atemporal de beleza, que fundamentava as proposições do classicismo, lançaram os primeiros alicerces da estética moderna. Além de suscitarem a questão da beleza relativa, atrelada à valorização de uma abordagem do homem pelo viés da sua identidade nacional, em detrimento das abordagens universalizantes do homem, os românticos também desencadeiam uma oposição contra a modernidade burguesa, focalizando principalmente as funestas consequências da ideologia do progresso capitalista, quer no âmbito do indivíduo, que experimenta a angústia da alienação e da fragmentação do eu, quer no âmbito coletivo, com as inúmeras adversidades geradas pelas grandes cidades. 
Os empreendimentos românticos permitem concluir que, na primeira metade do século XIX, já se configura um conceito de modernidade estética tal como o concebemos hoje, que se caracteriza como luta em duas frentes, contra a tradição literária e contra a sociedade capitalista. Afeitos desde o início a atitudes radicais, os artistas modernos transformam a criação artística em instrumento de crítica política e ideológica à mentalidade burguesa.

Tendo desenvolvido uma consciência apurada acerca das mudanças que o contexto histórico acarreta na mente dos indivíduos e na concepção do belo, os românticos contribuem, ainda, para consolidar um terceiro aspecto que define a modernidade estética, que é a oposição a si mesma. Em pleno contexto romântico, Baudelaire avulta como um dos primeiros grandes críticos da arte produzida por seus contemporâneos. Concebendo "a fantasia como uma elaboração guiada pelo intelecto" e entendendo a "desumanização do sujeito lírico como necessidade histórica" (CALINESCU, 1987, p. 37), Baudelaire busca esvaziar a poesia dos sentimentalismos, libertando-a do factual, do subjetivo e da inspiração.

Baudelaire inaugura um tempo em que os escritores vão submeter a tradição, o sistema econômico e a própria necessidade de modernização da arte a um permanente escrutínio da razão crítica, o que acaba por gerar uma poética de tensões e contradições, que expressa os conflitos, muitas vezes insolúveis, de sujeitos líricos fragmentados e mergulhados em dúvidas existenciais dolorosas.

Este trabalho faz parte de um projeto mais amplo, que venho desenvolvendo nos últimos anos, que busca analisar algumas das tensões geradas pelo tríplice embate dos poetas contra o passado, contra o sistema social e contra a própria modernidade, verificado ao longo do processo de modernização da poesia portuguesa, iniciado no século XIX por românticos, realistas e simbolistas, consolidado pelos modernistas e reelaborado, de inúmeras formas, pelos contemporâneos.

Um dos fundadores da modernidade estética em Portugal é Antero de Quental (18421891), líder da Geração de 70, que instalou o movimento realista neste país. Segundo o poeta, sua geração foi a primeira a ter consciência da necessidade de romper com o passado. Mas a atitude heroica, que impulsiona para a ruptura, também lança o artista no caos, "estado terrível de espírito" que prepara a gestação do novo, segundo palavras do próprio poeta ${ }^{2}$. Ao

\footnotetext{
${ }^{2}$ Depoimento realizado numa carta ao lusitanista alemão Wilhelm Storck (QUENTAL, 2014. p. 6).
} 
discorrer sobre a arte moderna, Fernando Pessoa enfatiza o papel decisivo da geração de Antero de Quental:

A transformação social que se tem estado a operar em Portugal, nas últimas três gerações e que culminou na implantação da República, tem sido acompanhada, como é natural, de uma transformação concomitante na literatura portuguesa. Os dois fenômenos têm uma origem comum nas modificações essenciais que, com rapidez crescente, se têm verificado nas próprias bases da consciência nacional. Atribuir a transformação literária à política, ou a política à literária, seria igualmente errôneo. Ambas são manifestações de uma transformação fundamental que a consciência nacional tem experimentado e pela qual está ainda passando.

Da transformação literária, representada por um rompimento definido com as tradições literárias portuguesas, pode-se considerar o ponto de partida Antero de Quental e a Escola de Coimbra, embora necessariamente precedida de prenúncios e tentativas [...]. (PESSOA, 1986, p. 419)

Para Pessoa, a modernidade estética é um fenômeno que se desenvolve concomitantemente, de maneira paralela, à modernização social e política, embora as duas manifestações pertençam a esferas distintas. De maneira ambígua, ainda que partilhem do mesmo entusiasmo da burguesia pela ideologia do progresso e pelo racionalismo cientificista, os escritores realistas empreenderam uma oposição sistemática à sociedade capitalista em expansão, desencadeando diversas lutas políticas e ideológicas, que visavam legitimar padrões sociais de liberdade e igualdade. Desse modo, almejavam definir novos contornos da identidade nacional, em sintonia com certos avanços culturais já promovidos em países mais desenvolvidos da Europa.

Nos primeiros anos do século XX, os escritores da Geração de Orpheu dão continuidade ao processo de renovação da literatura, inaugurando o movimento modernista em Portugal. Assumindo conotações específicas em cada país, o termo refere-se a uma busca específica da modernidade (CALINESCU, 1987, p. 74), envolvendo alguns aspectos culturais, de engajamento com os valores progressistas, tanto no sentido iluminista de emancipação do ser humano, quanto no sentido de desenvolvimento tecnológico, e também aspectos artísticos relacionados a uma espécie de esteticismo cosmopolita, que marca as gerações de escritores surgidas nesse momento. Trata-se, portanto, de movimento literário e cultural, que congrega uma infinidade de propostas e projetos coletivos, além de uma infinidade de iniciativas individuais. 


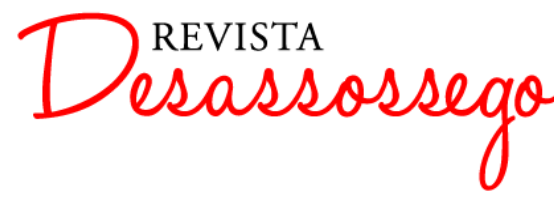

DESASSOSSEGO 15 | JUN/2016 | ISSN 2175-3180

DOI: http://dx.doi.org/10.11606/issn.2175-3180.v8i15p6-16

Os projetos diversificados das vanguardas históricas, que influenciaram decisivamente os escritores modernistas, estavam relacionados à ideia de renovação radical e tinham em comum com a estética moderna a crítica à tradição. Desse modo, embora articuladas às condições históricas do período, marcado por revoluções e guerras mundiais, as vanguardas inserem-se também na tradição da ruptura, teorizada por Octavio Paz, que se iniciou com as experiências poéticas de Edgard Allan Poe, Walt Withman, Charles Baudelaire, Arthur Rimbaud e Stéffane Mallarmé.

O autoritarismo dos manifestos e o radicalismo dos procedimentos artísticos das vanguardas têm muito a ver com a origem militar do termo. A força de choque e as propostas destrutivas, noções herdadas de táticas de guerra, são adotadas por quase todos os grupos. Tanto a bofetada, invocada por Tzara, quanto o canto à violência dos futuristas, bem como a agressividade das práticas dadaístas e expressionistas eram vistas como estratégias para destruir modelos congelados de percepção sensorial e mudar o modo de recepção da arte, como preparação para uma reorganização revolucionária da vida cotidiana. (HUYSSEN, 1987, p. 13-14).

Ao introduzir um elemento automático, inconsciente e irreflexivo na percepção e na experiência estética, o choque deveria estabelecer violenta ruptura com os hábitos formais estabelecidos, minando a arte institucionalizada da sociedade capitalista e reintegrando a arte na vida, o que constituiu uma das manifestações mais ousadas da permanente autocrítica promovida pela estética moderna.

Num contexto de crise econômica e política, caracterizado pela instabilidade da Primeira República (1910-1926), gerada pelas dissidências internas do Partido Republicano e pelas tensões sociais entre a grande burguesia (associada ao capitalismo estrangeiro, ao clero e à Monarquia) e as classes médias urbanas, de Lisboa e do Porto, que vão culminar no estabelecimento da ditadura de Salazar (1926-1975), a Geração de Orpheu teve um papel essencial na consolidação de uma arte bastante afinada com as experiências estéticas da época. São exemplos de experimentação poética, na linha das vanguardas, grande parte da obra de Almada Negreiros, os poemas dadaístas de Mário de Sá-Carneiro, o longo poema intitulado "Chuva oblíqua", cuja técnica de construção, muito próxima à do cubismo de Picasso, embora de motivação muito diversa, foi denominada por Fernando Pessoa de interseccionismo, além do sensacionismo de inspiração futurista que caracteriza a poesia de Álvaro de Campos e de Alberto Caeiro. 


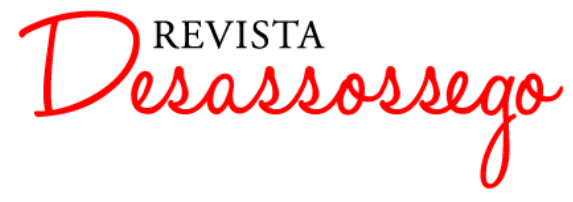

Curiosamente, porém, a Geração de Orpheu, embora alinhada com a rebeldia radical dos movimentos de vanguarda, também vai empreender intenso diálogo com a tradição clássica. Grande parte da obra de Fernando Pessoa e Sá-Carneiro não pode ser compreendida sem os fundamentos neoplatônicos que consolidam a visão de mundo e a concepção de arte dos dois poetas.

Não se pode esquecer, ainda, que Ricardo Reis produz uma poesia moldada em rígida disciplina mental, indo buscar no mundo clássico dos gregos e romanos a principal motivação de seus versos. O médico helenista, conforme informações biográficas criadas por Pessoa para seu personagem, explicitadas em uma das famosas cartas a Casais Monteiro, fundamenta-se nas teorias poéticas de Horácio e apoia-se em doutrinas filosóficas antigas como o epicurismo e o estoicismo, principais fontes das mensagens quase didáticas de sua poesia, que aconselha serenidade e contenção diante do mundo, sempre numa forma que adota características gerais do classicismo.

A escolha do patrono, Orfeu, que dá o título à revista fundada pelo grupo, não foi, portanto, gratuita. Notável herói da mitologia grega, figura central nos relatos sobre as origens de doutrinas religiosas e filosóficas do mundo antigo, Orfeu também ficou conhecido como poeta, músico e cantor. Tendo conduzido seu povo da selvageria para a civilização, Orfeu teria desempenhado relevante papel de educador da humanidade. Iniciado nos mistérios do ocultismo, teria desenvolvido sua formação religiosa e filosófica viajando pelo mundo e, ao retornar do Egito, teria sido responsável pela divulgação, na Grécia, dos mistérios órficos, dos quais Platão retirou subsídios para suas concepções sobre o mundo sensível e o mundo inteligível (BRANDÃO, 1991).

Grande parte da poesia escrita por Fernando Pessoa Ele Mesmo é alimentada por misteriosa saudade e pungente angústia metafísica, decorrente dessa visão platônica que fundamenta parte essencial da visão de mundo do poeta. Não é exagero afirmar que toda a poesia ortônima é perpassada por atormentada ânsia em conhecer esse mundo das essências, ao qual o poeta sempre se refere como sendo o Além: "Minha alma é lúcida e rica,/E eu sou um mar de sargaço -/ Um mar onde bóiam lentos/ Fragmentos de um mar de além...” (PESSOA, 1960, p. 106).

Mergulhado em clima de nostalgia, o eu lírico sente-se possuído por uma espécie de saudade metafísica, que alimenta um desejo difuso de buscar sempre a realidade ideal, que paira acima e além da trivialidade do cotidiano. 


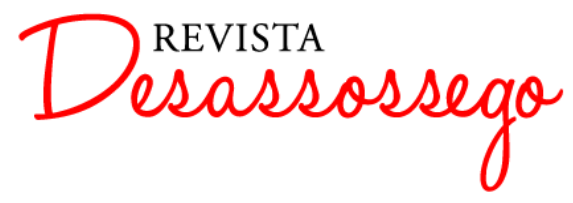

Fernando Pessoa encarna perfeitamente as principais características atribuídas ao mito de Orfeu. Trata-se de um poeta obcecado pelo desejo de ultrapassar a realidade material, em busca de um significado metafísico para a existência. Tal como Orfeu, ainda, caracterizase como um poeta atormentado pela dúvida e pela ânsia de atingir o sentido último do ser e do cosmos. Coerente com esse perfil, o poeta adota a ideia de poesia como forma de conhecer a si e ao mundo:

Neste mundo em que esquecemos Somos sombras de quem somos, $\mathrm{E}$ os gestos reais que temos No outro em que, almas, vivemos, São aqui esgares e assomos. (...)

Sombra do corpo saudosa, Mentira que sente o laço Que a liga à maravilhosa Verdade que a lança, ansiosa, No chão do tempo e do espaço.

(PESSOA, 1960, p. 113)

A doutrina de Platão, que estabelece distinção radical entre o mundo sensível e o mundo inteligível, visível nos versos citados, fundou uma longa tradição nas produções culturais do Ocidente, sobretudo na poesia. Em linhas gerais, caracteriza-se pelo dualismo entre corpo e alma, matéria e espírito, inteligência e sensação; pela crença em um mundo abstrato autônomo; pelo espiritualismo, pela doutrina da reminiscência e pela crença na possibilidade de elevação do espírito para além do mundo sensível.

Antes, porém, de concluir, apressadamente, que esta simbiose entre duas tradições opostas, uma clássica e outra eminentemente moderna, seja exclusividade da obra dos poetas irmanados em torno da revista de Orpheu, convém ressaltar que também esta característica insere os primeiros modernistas portugueses na mais alta tradição da modernidade, que tem nesta ambiguidade uma de suas principais características.

Em Charles Baudelaire, um dos pilares da poesia moderna, a questão da modernidade é igualmente complexa e ambígua, como será também na concepção do nosso quase contemporâneo, Octavio Paz. Para ambos, a modernidade trabalha a um só tempo com os aspectos efêmeros da realidade e do ser, ligados ao tempo histórico, e com aspectos relacionados a um tempo, criado pela obra de arte, que transcende o momento relacionado ao cotidiano e à efemeridade. 


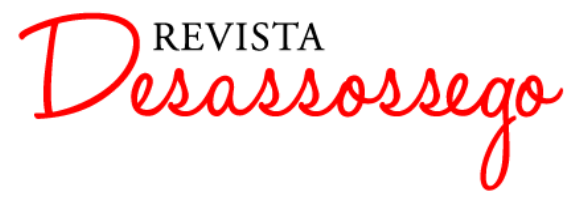

Para Baudelaire, é pela imaginação que o poeta penetra além da banalidade das aparências observáveis, em direção a um mundo de correspondências, onde a efemeridade e a eternidade se encontram, formando misteriosa simbiose, como se lê nos versos do poema "Elevação", de Flores do Mal: "Vai mais, vai mais além do lodo repelente,/Vai te purificar onde o ar se faz mais fino,/E bebe, qual licor translúcido e divino,/ O puro fogo que enche o espaço transparente" (BAUDELAIRE, 1985, p. 113) Já se tornou antológica a frase de Baudelaire, que define: "A Modernidade é o transitório, o efêmero, o contingente, é a metade da arte, da qual a outra metade é o eterno e o imutável" (1988, p. 174). Portanto, ser moderno não é fazer poesia apenas com o efêmero da vida cotidiana. Ser moderno implica um mergulho na efemeridade para atingir as dimensões simbólicas e míticas da realidade e do ser.

Octavio Paz também vai definir a modernidade como uma estética da ambiguidade, que, instalada numa materialidade histórica, remete a uma realidade anterior, que transcende o mundo empírico e temporal:

A nostalgia moderna de um tempo original e de um homem reconciliado
com a natureza expressa uma atitude nova. Ainda que postule, como os
pagãos, a existência de uma idade de ouro anterior à história, não insere
essa idade em uma visão cíclica do tempo; o regresso à idade feliz não será
a consequência da revolução dos astros, mas da revolução dos homens.
Na verdade, o passado não volta: os homens, por um ato voluntário e
deliberado, inventam-no e instalam-no na história. (...) Não há outro
remédio senão afirmar, por mais surpreendente que pareça esta
proposição, que só a modernidade pode realizar a operação de volta ao
princípio original, pois só a idade moderna pode negar-se a si própria.
(PAZ, 1984, p. 56)

Voltando a Fernando Pessoa, é importante ressaltar que o idealismo platônico presente em sua obra, principalmente nas criações ortônimas, é permanentemente corroído pelo niilismo devastador, pela ironia e pelo ceticismo abúlico, que abalam os fundamentos da metafísica, na obra pessoana.

Tão importante quanto entender a presença do platonismo em sua obra é considerar a corrosão dos seus fundamentos ao longo da complexa e paradoxal obra pessoana. Se, de um lado, temos a produção ortônima, a corrobar o saudosismo, fundamentado em singular nostalgia do mundo das essências, de outro, temos o olhar desconstrutor de Alberto Caeiro, 
sem falar na fúria revolucionária de Álvaro de Campos, que investe contra os principais fundamentos metafísicos da cultura ocidental.

Se ter consciência do peso da vida é algo que atormenta Fernando Pessoa Ortônimo, seu heterônimo Alberto Caeiro vai propor uma poesia que seria fruto exclusivamente das sensações. "Pensar é estar doente dos olhos" (PESSOA, 1960, p. 135), afirma Caeiro, um sábio que nunca teve educação formal e que abomina todos os sistemas instituídos pela Civilização Europeia (religião, metafísica, etc.). Vivendo no campo, adota o paganismo como fonte de compreensão do universo e busca fazer poesia exclusivamente com as sensações que lhe chegam de sua contemplação do universo bucólico, sempre contaminadas por um ceticismo niilista e irônico.

Álvaro de Campos também assume um modo de fazer poesia que procura excluir a interferência do pensamento racional e expressar somente as sensações que tem diante do mundo moderno. Tal como a poesia de Caeiro, a de Campos segue uma forma livre de convenções, próxima da prosa, com versos irregulares, que são construídos ao sabor das emoções que fluem.

Enquanto Caeiro focaliza o campo, o ambiente predileto de Campos é o mundo moderno, das cidades, dos edifícios, das máquinas e das guerras. Num grau mais forte do que a produção ortônima, a poesia de Álvaro de Campos é marcada pela angústia metafísica, a dor de existir, o niilismo e, principalmente, a fragmentação interior. Álvaro de Campos representa o homem moderno dilacerado diante do mundo contemporâneo. Sua poesia é um grito de revolta e de rebeldia diante do mundo burguês, aproximando-se muito dos artistas de vanguarda do início do século XX. Em muitos poemas, revela influência do futurismo e do expressionismo.

Quanto ao embaralhamento de elementos díspares na elaboração de sua poesia, é necessário assinalar ainda que, se de um lado os fundamentos de uma arte que toca o transcendente são corroídos pelo niilismo irônico devastador, típico das vanguardas, também os vínculos com as vanguardas são desestruturados, em grande parte, por este mesmo impulso autodestruidor. A título de exemplo, recordemos alguns versos da "Ode Triunfal", de Álvaro de Campos:

Em febre e olhando os motores como a uma Natureza tropical Grandes trópicos humanos de ferro e fogo e força Canto, e canto o presente, e também o passado e o futuro Porque o presente é todo o passado e todo o futuro 


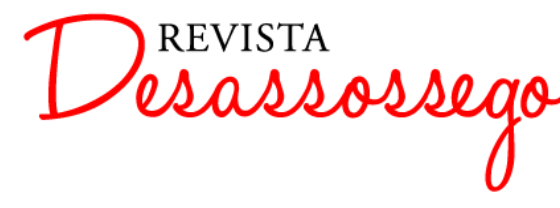

DESASSOSSEGO 15 | JUN/2016 | ISSN 2175-3180

DOI: http://dx.doi.org/10.11606/issn.2175-3180.v8i15p6-16

E há Platão e Virgílio dentro das máquinas e das luzes eléctricas

Só porque houve outrora e foram humanos Virgilio e Platão,

E pedaços do Alexandre Magno do século talvez cinquenta,

Átomos que hão-de ir ter febre para o cérebro do Ésquilo do século cem

Andam por estas correias de transmissão e por estes êmbolos e por estes volantes,

Rugindo, rangendo, ciciando, estrugindo, ferreando,

Fazendo-me um excesso de carícias ao corpo numa só carícia à alma.

Ah, poder exprimir-me todo como um motor se exprime!

Ser completo como uma máquina!

Poder ir na vida triunfante como um automóvel último-modelo!

(PESSOA, 1960, p. 260)

Somente uma leitura ingênua poderia contentar-se em apontar no poema características futuristas. Não se pode deixar de ler as pequenas investidas da ironia cética de Pessoa, que o levam a adotar um procedimento completamente ambíguo em relação às propostas de Marinetti. Ao longo de todo o poema, pontuam as farpas ferinas de uma poética que se mostra futurista ao mesmo tempo que zomba, sorrateiramente, das insolências desta vanguarda, que propunha a destruição radical de todo passado e de tudo o que fosse humano.

Com base nestas reflexões acerca da poesia de Fernando Pessoa, podemos concluir que a Geração de Orpheu, imbricada no trajeto revolucionário da Modernidade, promove uma ruptura com a tradição ao mesmo tempo que mergulha sua atividade criativa no inconsciente coletivo dos arquétipos, indo buscar nos mitos antigos as bases para o seu questionamento acerca do homem e da vida. Desse modo, a Geração cumpre seu papel de movimento revolucionário na poesia portuguesa do século $\mathrm{XX}$, configurando, principalmente com a obra de Fernando Pessoa, o duplo movimento de progresso e de retorno às origens da poesia ocidental.

\section{REFERÊNCIAS}

BAUDELAIRE, C. As flores do mal. Rio de Janeiro: Nova Fronteira, 1985.

O pintor da vida moderna. In COELHO, T. (Org.). A modernidade de Baudelaire.

Textos inéditos selecionados por Teixeira Coelho. Trad. Suely Cassal. Rio de Janeiro: Paz e Terra, 1988. p. 159-212.

BRANDÃO, J. “Orfeu”. In:__. Dicionário mítico-etimológico. Petrópolis: Vozes, 1991. v. 2, p. 196-204. 
CALINESCU, M. Five faces of modernity: modernism, avant-garde, decadence, kitsch, postmodernism. Durham: Duke University Press, 1987.

HUYSSEN, A. After the great divide; modernism, mass culture, postmodernism. Bloomington: Indiana University Press, 1987.

PAZ, Octavio. Os filhos do barro; do romantismo à vanguarda. Tradução de Olga Savary. Rio de Janeiro: Nova Fronteira, 1984.

PESSOA, F. Obra poética. Rio de Janeiro: José Aguilar, 1960. Obras em prosa. Rio de Janeiro: José Aguilar, 1986.

QUENTAL, Antero. “Carta Autobiográfica a Wilhelm Storck”. In: As tendências gerais da filosofia na segunda metade do século XIX. Lisboa: Centauro, 2014. p. 6.

TELES, Gilberto Mendonça. Vanguarda europeia e modernismo brasileiro; apresentação e crítica dos principais manifestos vanguardistas. Petrópolis: Vozes, 1972. p. 117. 